era we would aim to augment pulmonary blood flow as soon as possible to achieve what pulmonary arterial growth is possible. Unfortunately, even when this approach was aggressively employed (case 1), satisfactory pulmonary vascular development has not been achieved.

Our study expands on a theme identified by McElhinney and colleagues, ${ }^{2}$ who noted that patients with a JAG1 mutation and PA/VSD had a poor outcome, with 6 of 8 patients (75\%) not surviving treatment in infancy. The survival rate in their patient group mirrors that of our cohort and highlights the severity of the condition. These results have implications for clinical decision making and management of PA in the context of AGS and allow us to calibrate expectations for those requiring surgery.

We acknowledge the contributions of Prof Tim Cartmill, Dr David Johnson, Dr Graham Nunn, Dr Ian Nicholson, and Dr Stephen Cooper, who were involved in the clinical management of these patients.

\section{References}

1. Kamath BM, Spinner NB, Emerick KM, Chudley AE, Booth C, Piccoli DA, et al. Vascular anomalies in Alagille syndrome: a significant cause of morbidity and mortality. Circulation. 2004;109:1354-8.

2. McElhinney DB, Krantz ID, Bason L, Piccoli DA, Emerick KM, Spinner NB, et al. Analysis of cardiovascular phenotype and genotypephenotype correlation in individuals with a JAG1 mutation and/or Alagille syndrome. Circulation. 2002;106:2567-74.

3. Loomes KM, Underkoffler LA, Morabito J, Gottlieb S, Piccoli DA, Spinner NB, et al. The expression of Jaggedl in the developing mammalian heart correlates with cardiovascular disease in Alagille syndrome. Hum Mol Genet. 1999;8:2443-9.

4. Kamath BM, Krantz ID, Spinner NB, Heubi JE, Piccoli DA. Monozygotic twins with a severe form of Alagille syndrome and phenotypic discordance. Am J Med Genet. 2002;112:194-7.

5. Reddy VM, McElhinney DB, Amin Z, Moore P, Parry AJ, Teitel DF, et al. Early and intermediate outcomes after repair of pulmonary atresia with ventricular septal defect and major aortopulmonary collateral arteries: experience with 85 patients. Circulation. 2000; 101:1826-32.

\title{
Infant arch reconstruction during total system perfusion
}

\author{
Aimee B. Gardner, BS, CCP, and Pirooz Eghtesady, MD, PhD, Cincinnati, Ohio
}

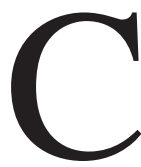

urrently, neonatal arch reconstruction requires the use of circulatory arrest or, predominantly, regional cerebral perfusion techniques. ${ }^{1}$ With regional perfusion, the question remains as to the adequacy of brain perfusion. ${ }^{2,3}$ Recent clinical and experimental evidence suggests that, with all techniques, systemic perfusion is sacrificed and unwanted effects of deep hypothermia remain. With the use of the INVOS cerebral oximeter (Somanetics, Troy, Mich), changes in the regional cerebral oxygen saturation are now noninvasively and continuously monitored, allowing for the comparison of different techniques. We present a case of successful aortic arch reconstruction in an infant using a novel technique that allows total cerebral as well as systemic perfusion during arch reconstruction.

\section{Clinical Summary}

A 6-month-old infant with Shone's anomaly, who had undergone a previous repair of coarctation of aorta and total anomalous

From the Cincinnati Children's Hospital Medical Center, Cincinnati, Ohio. Received for publication Oct 25, 2006; accepted for publication Oct 30, 2006.

Address for reprints: Aimee B. Gardner, BS, CCP, Cincinnati Children's Hospital Medical Center, Cardiothoracic Surgery, 3333 Burnet Ave, MLC 2004, Cincinnati OH 45229 (E-mail: Aimee.gardner@cchmc.org).

J Thorac Cardiovasc Surg 2007;133:1096-8

$0022-5223 / \$ 32.00$

Copyright @ 2007 by The American Association for Thoracic Surgery doi:10.1016/j.jtcvs.2006.10.072 pulmonary venous return, developed a new arch that narrowed between the innominate artery and left carotid takeoff. Because of worsening left ventricular hypertrophy, increased left ventricular end diastolic pressure, and a mild increase in right-sided pressures, reintervention was recommended.

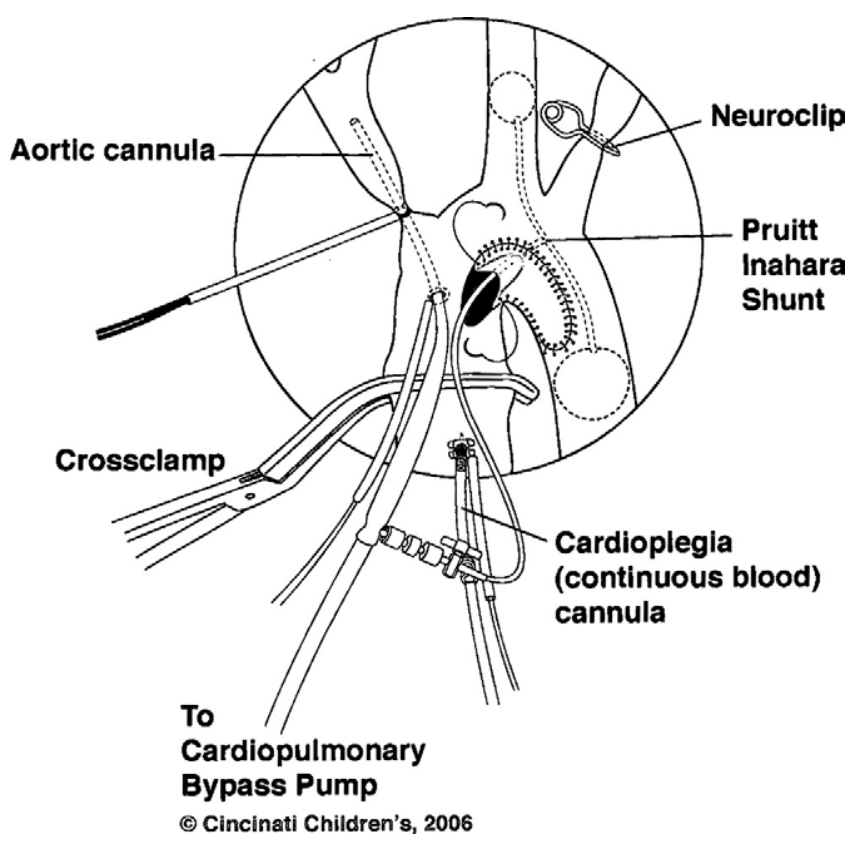

Figure 1. Positioning of Pruitt-Inahara shunt for aortic arch repair. CPB, cardiopulmonary bypass. 


\section{Brain Saturation vs. Time}

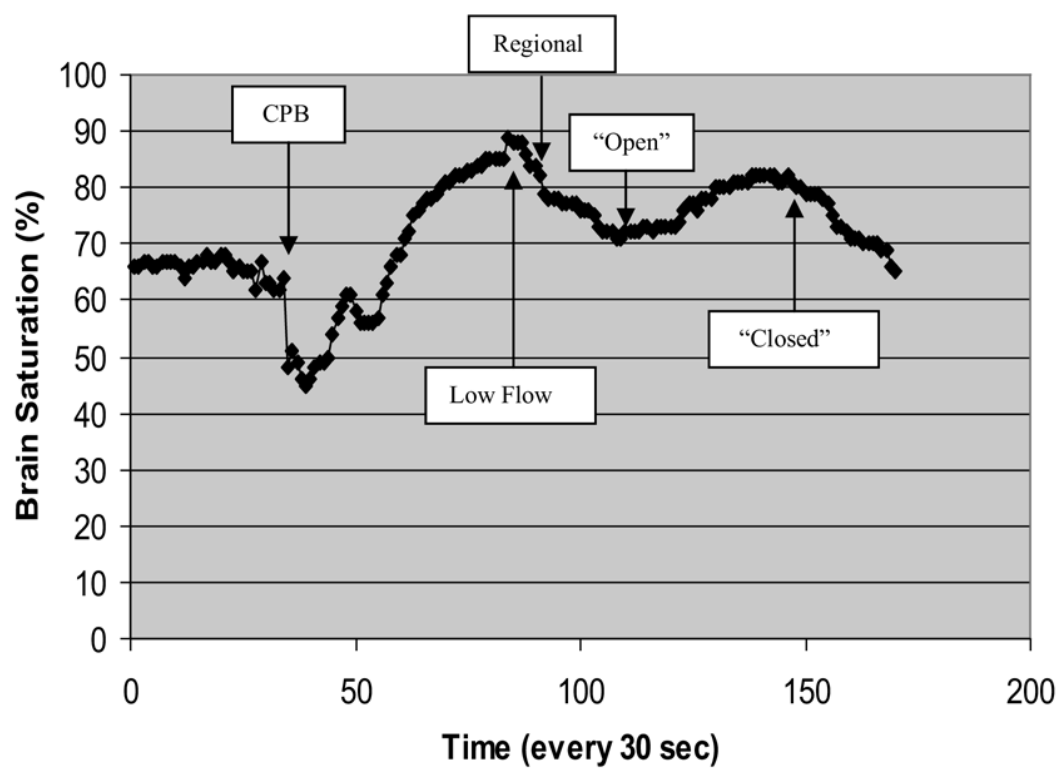

Figure 2. Cerebral oxygen saturations is shown (y-axis) versus time (x-axis). CPB, Low Flow, and Regional refer to initiation of these respective perfusion techniques. Open and Closed refer to opening and closing of the Pruitt shunt. CPB, cardiopulmonary bypass.
A cerebral saturation monitor was employed during surgery. After redo sternotomy, the ascending aorta was cannulated just proximal to the takeoff of the innominate artery. With venous cannulation of the right atrial appendage, bypass was initiated and the patient was cooled to $22^{\circ} \mathrm{C}$. Regitine $(0.2 \mathrm{mg} / \mathrm{kg})$ was given to promote whole body cooling. $\mathrm{pH}$ stat protocol and superoxia were followed once the patient reached $24^{\circ} \mathrm{C}$.

The aortic cannula was then repositioned into the innominate artery and snared. Regional perfusion was initiated at $30 \mathrm{~mL} \cdot \mathrm{kg}^{-1} \cdot \mathrm{min}^{-1}$. Simultaneously, a cardioplegic cannula was placed in the aortic root, through which the coronaries were continuously perfused with blood after the crossclamp was applied (eliminating cardiac ischemic time). The left carotid and left subclavian artery were snared and then transiently occluded along with the distal aortic arch.

After incising the aortic arch, 1 limb of the 8F Pruitt-Inahara carotid shunt (LeMaitre Vascular, Burlington, Mass) was introduced into the left carotid and attached to the side port of the arterial cannula (Figure 1). Before the shunt was opened, baseline arterial line pressure was noted. The shunt was opened and flow was increased to match the previous pressure (a difference of about $60 \mathrm{~mL} / \mathrm{min}$ ). With bihemispheric perfusion, cerebral saturation was seen to increase from low 70 s to low 80 s within 15 minutes (Figure 2).

The distal arch snare was then released, and the other limb of the Pruitt-Inahara shunt was then placed into the descending aorta to maintain perfusion of the lower body. Patch reconstruction of the aortic arch was begun with a Shelhigh patch (Shelhigh, Inc, Union, $\mathrm{NJ}$ ). Limited back-bleeding was noted from around the balloon in the distal arch, which was easily managed with a pump sucker. Bicerebral perfusion, provided by the Pruitt-Inahara shunt, was maintained for 44 minutes while the arch repair was completed. Normal perfusion and rewarming were followed with a period of modified ultrafiltration after completion of cardiopulmonary bypass. Postoperative recovery was uneventful. At her last follow-up, 24 months since her operation, the patient continues to do well without further evidence of any arch obstruction.

\section{Discussion}

Although the Pruitt-Inahara shunt (LeMaitre Vascular) was originally developed for adult carotid endarterectomies, it has also been used for other vascular procedures; it has never been reported, however, in the pediatric setting. Yet it is a good tool for the described purpose because it can provide cerebral and systemic blood flow while reducing risk of vessel trauma as a result of clamping. We observed increased cerebral saturation in response to bilateral cerebral perfusion. Whether this translates into improved neurologic outcomes (and whether bilateral cerebral perfusion is beneficial) is under investigation. Cerebral hyperperfusion of the brain is a possible risk, ${ }^{4}$ as the degree of flow into each limb of the arterial inflows is not measured. Simultaneous monitoring of upper and lower body arterial pressures could eliminate this risk.

We employed hypothermia to increase the safety of our procedure. Greater experience with such an approach may allow avoidance of hypothermia in the future. In turn, with less cooling, bypass times may be shortened and a host of coagulation issues resolved. ${ }^{5}$ Finally, we did have some difficulty with back-bleeding around the distal balloon; future shunt modifications could solve this problem and allow for further implementation of this technique in smaller infants.

\section{References}

1. Ungerleider R. Practice patterns in neonatal cardiopulmonary bypass pediatric cardiac surgery. Semin Thorac Cardiovasc Surg Pediatr Card Surg Аппи. 2004;7:172-9. 
2. Andropoulos DB, Diaz LK, Fraser CD Jr, McKenzie ED, Stayer SA. Is bilateral monitoring of cerebral oxygen saturation necessary during neonatal aortic arch reconstruction? Anesth Analg. 2004;98:1267-72.

3. Andropoulos DB, Stayer SA, McKenzie ED, Fraser CD Jr. Regional low flow perfusion provides comparable blood flow and oxygenation to both cerebral hemispheres during neonatal aortic arch reconstruction. J Thorac Cardiovasc Surg. 2003;126:1712-7.
4. Andropoulos DB, Stayer SA, McKenzie ED, Fraser CD Jr. Novel cerebral physiologic monitoring to guide low flow cerebral perfusion during neonatal aortic arch reconstruction. J Thorac Cardiovasc Surg. 2003;125:491-9.

5. Kiraly L, Prodan Z. Continuous system perfusion via collaterals at moderate hypothermia in aortic arch repairs in neonates. Croat Med $J$. 2002;43:656-9.

\section{Thoracic aortic aneurysm in a young infant with congenital aortic stenosis}

Dante Picarelli, MD, ${ }^{a}$ Serrana Antunez, MD, ${ }^{a}$ Christian Kreutzer, MD, ${ }^{\mathrm{b}}$ Guillermo Touyá, MD, ${ }^{a}$ Diego Abdala, MD, ${ }^{\mathrm{a}}$ Luis Ligüera, MD, ${ }^{a}$ and Gabriel Echegaray, MD, ${ }^{a}$ Montevideo, Uruguay, and Buenos Aires, Argentina

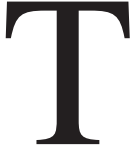
horacic aortic aneurysm is uncommon in pediatric patients. ${ }^{1,2}$ Its association with congenital valvar aortic stenosis is rarely seen in infants. ${ }^{3}$ To the best of our knowledge there have been no prior reports of surgical treatment of an aortic isthmus aneurysm in an infant with critical aortic stenosis.

We report our experience with this uncommon association in a 45-day-old infant who required aneurysmectomy and aortic balloon dilation.

\section{Clinical Summary}

Shortly after birth, congestive heart failure developed in a full-term male neonate weighing $3200 \mathrm{~g}$.

Doppler echocardiography revealed a critical valvular aortic stenosis with an adequate aortic annulus and left ventricle and a severely impaired ventricular function. At the level of the aortic isthmus, an "extremely dilated" ductus arteriosus with a bidirectional shunt was described.

On the second day of age, the patient underwent a successful percutaneous balloon valvotomy with a right carotid approach. The peak systolic gradient decreased from 80 to $30 \mathrm{~mm} \mathrm{Hg}$, and the ejection fraction was $25 \%$. The aortogram showed no evidence of residual aortic regurgitation but did show a pathologic saccular dilation of the lateral aspect of the aortic isthmus (Figure 1).

\footnotetext{
From the Division of Cardiac Surgery and Intensive Care Unit, Congenital Cardiac Unit, American Cardiac Center, American Hospital, ${ }^{a}$ Montevideo, Uruguay; and Division of Cardiac Surgery, Hospital de Niños Ricardo Gutierrez,' Buenos Aires, Argentina.

Received for publication Dec 9, 2006; accepted for publication Dec 14, 2006.

Address for reprints: Dante Picarelli, MD, Unidad de Cardiopatías Congénitas, Centro Cardiológico Americano, Sanatorio Americano, Isabelino Bosch 2469, Montevideo 11600 Uruguay (E-mail: picarelli54@hotmail. com).

J Thorac Cardiovasc Surg 2007;133:1098-9

$0022-5223 / \$ 32.00$

Copyright $\odot 2007$ by The American Association for Thoracic Surgery doi:10.1016/j.jtcvs.2006.12.018
}

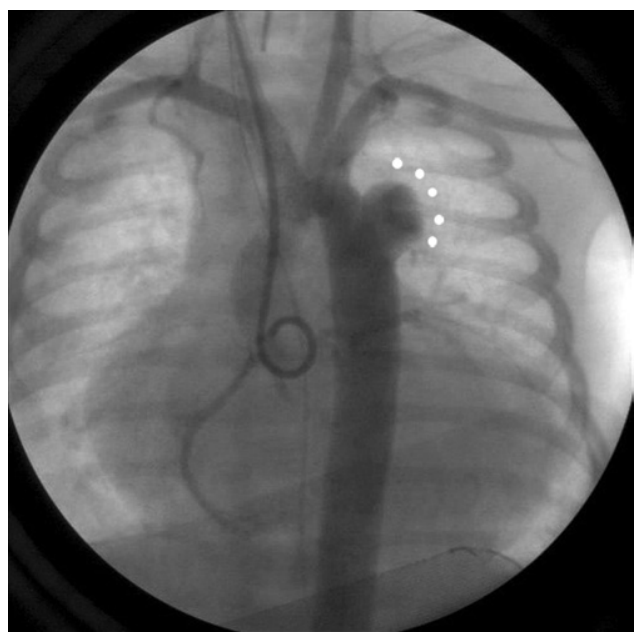

Figure 1. Aortogram showing a large aortic aneurysm involving the aortic isthmus.

Despite the risk of spontaneous aortic rupture or dissection, we decided to wait for left ventricular recovery before surgical repair was attempted. The infant remained in stable condition after treatment with diuretics, vasodilators, and digoxin.

Regular echocardiography surveillance did not show any sign of enlargement.

Six weeks after birth, when the left ventricular function partially improved (ejection fraction 40\%), we decided to perform the surgical correction.

The operation was performed without cardiopulmonary bypass through a standard left thoracotomy. Operative findings confirmed a saccular aneurysmatic dilation, measuring $18 \times 10$ $\mathrm{mm}$, located at the aortic isthmus. The ductus arteriosus was not involved, and the aortic wall was noted to be more fragile than normal, without adhesions to the lung, esophagus, or other mediastinal structures.

The aneurysm was dissected and handled with special care; the aorta was crossclamped between the left carotid and the subclavian 